\section{Commentary: Standing on similar, but different, shoulders}

\author{
Sanjeet Patel, MD, PhD, ${ }^{\mathrm{a}}$ and Anthony W. Kim, $\mathrm{MD}^{\mathrm{b}}$
}

In 1975, Martin and Melamed ${ }^{1}$ established a framework in which thoracic surgeons could categorize lung cancers presenting with additional malignant nodules as being simultaneous primary lung cancers (SPLCs) or intrapulmonary metastases (IPMs). Over the course of nearly half a century, their rubric has weathered the challenges, augmentations, and refinements with considerable success, whether at the individual patient level or on a larger scale. In this regard, their contribution has served as a reference point in the understanding of SPLCs and IPMs. As such, thoracic surgeons stand on their shoulders when working to advance clinical knowledge in this realm.

Through the inclusion of objective data in the form of molecular profiling using next-generation sequencing (NGS) DNA sequencing, Zheng and colleagues ${ }^{2}$ in this issue of The Journal were able to distinguish whether histologically similar lesions represented SPLCs or IPMs. Using a 4-gene NGS panel that included KRAS, EGFR, NRAS, and BRAF driver mutations, they demonstrated that among 41 specimens from 18 patients with histologically similar lesions, conventional histologic examination misdiagnosed $22 \%$ of the specimens that were otherwise captured correctly by NGS. Equally interesting is that of the patients with SPLCs identified via molecular profiling, $44 \%$ were downstaged from their histologic staging based on NGS and, of these downstaged patients, $50 \%$ possibly received unnecessary adjuvant therapy given their NGS-based restaging. Cumulatively, these results highlight the potential of NGS that could improve on the classification of lesions in the context of multifocal disease.

Despite the outstanding implications of this study, some of the enthusiasm must be tempered by the fact that in

\footnotetext{
From the ${ }^{\mathrm{a} C a r d i o v a s c u l a r}$ Thoracic Institute and ${ }^{\mathrm{b}}$ Division of Thoracic Surgery, Keck School of Medicine, University of Southern California, Los Angeles, Calif. Disclosures: Authors have nothing to disclose with regard to commercial support. Received for publication Dec 12, 2019; revisions received Dec 12, 2019; accepted for publication Dec 12, 2019; available ahead of print Jan 7, 2020.

Address for reprints: Anthony W. Kim, MD, Keck School of Medicine, The University of Southern California, 1510 San Pablo St, Suite 514, Los Angeles, CA 90033 (E-mail: anthony.kim@med.usc.edu).

J Thorac Cardiovasc Surg 2020;160:e81-2 $0022-5223 / \$ 36.00$

Copyright (c) 2020 Published by Elsevier Inc. on behalf of The American Association for Thoracic Surgery

https://doi.org/10.1016/j.jtcvs.2019.12.060
}

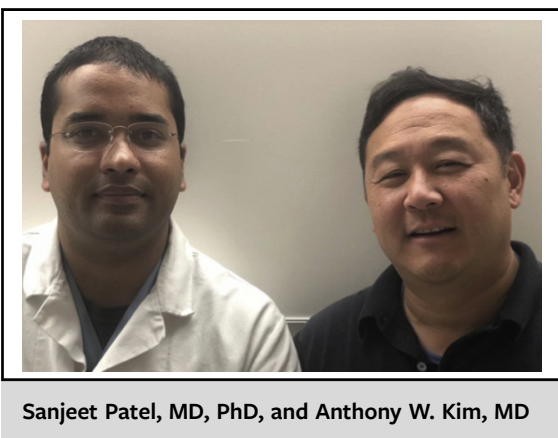

$$
\begin{aligned}
& \text { CENTRAL MESSAGE } \\
& \text { Molecular profiling with genomic } \\
& \text { sequencing may enhance the } \\
& \text { ability to distinguish between } \\
& \text { simultaneous primary lung can- } \\
& \text { cers and intrapulmonary metas- } \\
& \text { tases in non-small cell lung } \\
& \text { cancers. }
\end{aligned}
$$

approximately one third of the patients, there was an inability to account for the full spectrum of tumor heterogeneity with the smaller gene panel, thus potentially contributing to inaccurate NGS-based downstaging. With their 4-gene NGS panel, discordance was ascribed to 5 patients labeled as SPLC because the second nodule(s) lacked an identifiable driver mutation. Without an expanded secondary analysis using whole-exome sequencing, as well as controls across the entire panel of tumors to explore their power to detect all mutations, this finding is difficult to separate from a potential false negative. An expanded panel of genes may help capture some genomic SPLCs with confidence; however, $10 \%$ to $15 \%$ of tumors have subclonal mutations in KRAS, EGFR, or p53 and, therefore, issues with sampling may persist. ${ }^{3}$ A key finding in the paper is that on re-review of the histopathology, the concordance between full genetic data and the pathology review was excellent, suggesting its advantageous role in enhancing expert histopathologic reviews.

Ultimately, the authors' 4-gene NGS panel is a natural extension of the findings from the TRACERx consortium, ${ }^{3}$ and authors should be credited for cleverly applying the concepts behind this consortium into the area of multifocal disease. In this era of thoracic surgery, using NGS to distinguish between SPLCs and IPMs is revealing the potential of great promise, and further investigation may yield additional results that suggest an absolutely necessary role in this context. The authors should be recognized for having 
added to the work of Martini and Melamed with similar effect, but in a different manner through adding foundational elements that shape a new paradigm in which SPLCs and IPMs can be evaluated. As their work establishes the preliminary findings for others to stand on, Zheng and colleagues most assuredly will demonstrate that they have broad shoulders as well.

\section{References}

1. Martini N, Melamed MR. Multiple primary lung cancers. J Thorac Cardiovasc Surg. 1975;70:606-12.

2. Zheng R, Shen Q, Mardekian S, Solomides C, Wang Z-X, Evans NR. Molecular profiling of key driver genes improves staging accuracy in multifocal non-small cell lung cancer. J Thorac Cardiovasc Surg. 2020;160:e71-9.

3. Jamal-Hanjani M, Wilson GA, McGranahan N, Birkbak NJ, Watkins TBK, Veeriah S, et al; TRACERx Consortium. Tracing the evolution of non-smallcell lung cancer. N Engl J Med. 2017;376:2109-21.
See Article page e71.

\section{Commentary: How to "spot" a leopard: It's in the genes}

\author{
John F. Lazar, MD
}

One of the truly important, yet confounding, questions in thoracic oncology is how to approach multifocal non-small cell lung cancer (NSCLC). It remains an elemental question in regard to our approach to preoperative staging - a critical time for both the patient and the clinicians. A moment when our treatment decisions have the longest reach of effect. The Tumor Board's task of deciphering the multifocal decision tree is an immensely tangled puzzle with no right answer glaring back at us no matter how hard we study it. Confounding matters further are the treatment pathway biases of each individual institution, tainting any ability to approach this problem from a uniform methodology.

The hope of next-generation sequencing (NGS) is to dispel the mystery of multifocal NSCLC. As long as we have tissue, we can hope to identify a synchronous primary lung cancer (SPLC) or intrapulmonary metastasis (IPM) simply by looking its genetic code.

Underlying this hope are a lot of assumptions, assumptions that require good science to parcel them out. In my mind, there are 2 elemental questions in regard to applying NGS to multifocal NSCLC: (1) when to test and (2) which is the best test.

From the Division of Thoracic Surgery, Department of Surgery, MedStar Georgetown University Hospital, Washington, DC.

Disclosures: Author has nothing to disclose with regard to commercial support.

Received for publication Dec 23, 2019; revisions received Dec 23, 2019; accepted for publication Dec 24, 2019; available ahead of print Jan 21, 2020.

Address for reprints: John F. Lazar, MD, Division of Thoracic Surgery/Department Surgery, MedStar Georgetown University Hospital, Washington, DC (E-mail: John.f.lazar@medstar.net).

J Thorac Cardiovasc Surg 2020;160:e82-3

$0022-5223 / \$ 36.00$

Copyright (c) 2020 by The American Association for Thoracic Surgery

https://doi.org/10.1016/j.jtcvs.2019.12.099
Check for updates

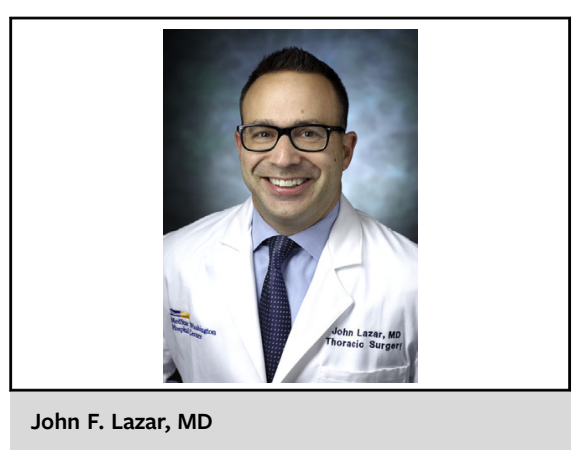

CENTRAL MESSAGE

Next-generation sequencing should be performed on all multifocal lung cancer, but how to apply this information requires further thought and investigation.

Zheng and colleagues ${ }^{1}$ has taken on the question of multifocal NSCLC by examining their own database using a custom NGS panel. According to the authors, this is the first paper to examine what happens when NGS is not employed on multifocal NSCLC.

From the 18 tumor pairs examined via NGS, 8 were downstaged from IPM to SPLC. This is a staggering $44 \%$ reduction in stage with obvious treatment implications, albeit in hindsight. Importantly, this study showed what we would hope to see from any applied technology: an improvement in accurately making a diagnosis. In this case, $22 \%$ of IPMs were rediagnosed as SPLC that histopathology assessment alone failed to correctly identify. In developing their own NGS, the authors took cost, specimen volume, and time to analyze into account to produce a test, according to the authors, that is cheap, reliable, quick, and comparatively requires very little tissue. 